\title{
How structural elements added by evolution from bacterial transporters to human SLC6 homologs have enabled new functional properties
}

Asghar M. Razavi ${ }^{1}$, George Khelashvili ${ }^{1}$, Harel Weinstein ${ }^{1,2 *}$

${ }^{1}$ Department of Physiology and Biophysics, Weill Cornell Medical College of Cornell

University, New York, NY, 10065, USA

${ }^{2}$ Institute for Computational Biomedicine, Weill Medical College of Cornell University, New

York, NY 10065, USA

*Correspondence and requests for materials should be addressed to H.W.

(haw2002@med.cornell.edu)

\begin{abstract}
Much of the structure-based mechanistic understandings of the function of SLC6A neurotransmitter transporters emerged from the study of their bacterial LeuT-fold homologs. It has become evident, however, that structural differences such as the long $\mathrm{N}$ - and C-termini of the eukaryotic neurotransmitter transporters impart an expanded set of functional properties to the eukaryotic transporters, which are not shared by the bacterial homologs that lack the structural elements that appeared later in evolution. However, mechanistic insights into some of the measured functional properties of the eukaryotic transporters, that have been suggested to involve these structural elements, are sparse. To learn how the structural elements added in evolution enable mechanisms of the eukaryotic transporters in ways not shared with their bacterial LeuT-like homologs, we focused on the human dopamine transporter (hDAT) as a prototype. We present the results of a study employing large-scale molecular dynamics simulations and comparative Markov State Model analysis of experimentally determined properties of the wild type and mutant hDAT constructs, which reveal a rich spectrum of interactions of the hDAT N-terminus and the mechanisms by which these contribute to regulation (e.g., by phosphorylation), or to entirely new phenotypes (e.g., reverse uptake efflux) added in evolution. We reveal separate roles for the distal and proximal segments of the much larger N-terminus shared by the eukaryotic transporters compared to the bacterial ones, consistent with the proposal that the size of this region increased during evolution to enable more, and different, modes of regulation that are not shared with the bacterial homologs.
\end{abstract}

Keywords: dopamine transport, SLC6 neurotransmitter transporters, evolutionary gain of function

\section{Background}

The dopamine transporter (DAT) is a member of the neurotransmitter:sodium symporter (NSS) family of proteins belonging to the solute carrier 6 (SLC6) family that performs the 
bioRxiv preprint doi: https://doi.org/10.1101/204164; this version posted January 30,2018 . The copyright holder for this preprint (which was not certified by peer review) is the author/funder, who has granted bioRxiv a license to display the preprint in perpetuity. It is made available under

reuptake of dopamine from the synaptic cleft into the presynaptic nerve required for neuronal signaling (1). The essential role of DAT, and of its closely related homologs - the serotonin and norepinephrine transporters (SERT and NET) - in signal termination at the synapse makes them important targets for psychostimulants such as cocaine and amphetamines, as well as for pharmaceutical treatment of a variety of disorders of the nervous system (2). Moreover, genetic modifications of the functions of these transporters $(3,4)$ have been implicated in diseases including Schizophrenia, Parkinson's, and Attention-deficit/hyperactivity disorder (ADHD). Reverse transport of the neurotransmitters (efflux) mediated by DAT and SERT, which has been shown to be affected by such disease-related mutations, is currently a very active topic of research on mechanisms of these membrane proteins (4-15).

Much has been learned about these mammalian neurotransmitter transporters from the investigation of structure and function of their bacterial homologs with which they share many structural and mechanistic properties (16-19). It has become clear, however, that important structural differences exist between the eukaryotic and bacterial proteins, the largest being the much longer $\mathrm{N}$ - and C-termini that have been proposed to be partially structured $(20,21)$. Notably, experimental data point to an involvement of these regions of structural difference in measured functional properties of the mammalian NSS (22-24). For example, the phosphorylation of the N-terminus has been implicated the efflux functions of the human DAT (hDAT) $(22,25)$, and our work has shown that the amphetamine (AMPH)-induced reverse transport (efflux) exhibited by DAT and SERT, but not by the bacterial analogs, is dependent on electrostatic interactions between the hDAT N-terminus and negatively charged phosphatidylinositol 4,5-biphosphate $\left(\mathrm{PIP}_{2}\right)$ lipids in the membrane $(29,36)$. Notably, the measured substrate uptake by DAT, a function it shares with the bacterial transporters, is not affected by this N-terminus interaction (35).

Structure-based mechanistic details of the mode in which eukaryotic NSS function is modulated by the involvement of the N-terminus are still sparse, but mechanistic insight from computational studies of hDAT has shown (26) that the N-terminus of DAT engages the $\mathrm{PIP}_{2}$ lipid component of membranes to achieve conformational changes related to function (CCRF). These include (i)-the transition of the DAT from outward-facing to inward-facing configurations (27), and (ii)-the release of the sodium ion from the Na2 binding site that is known to precede substrate transport $(28,29)$ and can serves as a monitor of the initial stages of the functional mechanism (30). The complexity of the different CCRF suggested that the $\mathrm{N}$-terminus/PIP 2 interactions supporting them may (1)-involve different modes of association with the membrane under various conditions (such as in the presence/absence of $\mathrm{PIP}_{2}$ ), and (2)-would be different for different hDAT constructs (e.g., when the N-terminus is phosphorylated or mutated). This reasoning provided a specific testable hypothesis about the mechanism by which new properties of the eukaryotic transporters, those that are not shared with the bacterial homologs, are enabled by the addition of the long $\mathrm{N}$ - and C-terminals.

To probe this hypothesis, and verify the relation between the experimental measurements and the specific modes in which the N-terminus participates, we undertook the present computational study of the modes of interaction of the N-terminus in hDAT with the rest of the structure, including the C-terminus, under various conditions and with modifications (phosphorylation, mutations) that have known functional consequences. Here we describe the results from extensive ensemble-level all-atom molecular dynamics simulations we used in this study that also included Markov State Model analysis of hDAT dynamics modulated by mutated and/or modified N-terminus constructs and conditions. The results reveal preferred modes of interaction of the N-terminus with the intracellular domains of hDAT, which can be directly associated with experimentally measured functional phenotypes of the transporter. We show how 
bioRxiv preprint doi: https://doi.org/10.1101/204164; this version posted January 30,2018 . The copyright holder for this preprint (which was not certified by peer review) is the author/funder, who has granted bioRxiv a license to display the preprint in perpetuity. It is made available under aCC-BY-NC-ND 4.0 International license.

these interaction patterns change under conditions that have been demonstrated to selectively affect efflux but not regular transport - e.g., PIP 2 depletion, mutations such as $\mathrm{R} 51 \mathrm{~W}$, the $\mathrm{K} 3 \mathrm{~A} / \mathrm{K} 5 \mathrm{~A}$ double mutation, or phosphomimic substitution, $\mathrm{S} / \mathrm{D}$, of Serine residues at positions 2, 4, 7, 12, and 13 to Aspartate $(22,31,32)$. Moreover, we verify, for the first time, the consistency of observations relating quantitative measures of the specific modes of interaction of the $\mathrm{N}$ terminus with the measured functional properties attributed to them.

The coherent and direct relation between experimentally determined effects of the mutations and conditions, and the interaction modes identified from the simulations, validates the computational results and mechanistic conclusions. Moreover, because the mechanistic inferences are described in atomistic detail, they offer specific experimentally testable predictions for further studies of SLC6 transporter function and of the structure-based relation between the function of bacterial and eukaryotic members of this family. In particular, the details of the rich spectrum of modes of interaction of the long N-terminus of hDAT that emerges from these studies reveal the different roles of the distal and proximal segments of the N-terminus in modulating specific functions of hDAT. As these are segments of the much larger $\mathrm{N}$-terminus shared by the eukaryotic transporters compared to the bacterial ones, the findings bring mechanistic support for our proposal that the size of this region increased during evolution so as to enable more, and different, modes of regulation that are not shared with the bacterial analogs. An example discussed in detail is the mechanistic explanation for experimentally determined differences in the effects on uptake versus efflux resulting from manipulation of the $\mathrm{N}$-terminus by partial truncation, mutations, and/or elimination of $\mathrm{PIP}_{2}$ interactions. This example further underscores the central role of this structural addition in the evolution from the bacterial LeuTlike members of this family.

\section{Results}

The full complement of MD simulation trajectories carried out specifically for this study as described in Methods, includes 50 statistically independent $\sim 1 \mu$ s-long trajectories for each of the four different conditions and constructs for which quantitative measurements of activity are available. As discussed before (30) the ensemble exploration of the configurational space of each construct/condition bolsters the statistical validity of the inferences and predictions from the simulation. The specific molecular systems investigated in this manner include: (i)-wild type hDAT in PIP $_{2}$-depleted membranes (hereafter referred to as "no-PIP 2 system"), (ii)-hDAT with the R51W mutation in the N-terminal domain, with the double $\mathrm{K} 3 \mathrm{~A}+\mathrm{K} 5 \mathrm{~A}$ mutation in the $\mathrm{N}$ terminus (termed "K3/5A system"), and with the first five N-terminal Ser residues substituted by Asp as a phosphomimic (termed "S/D construct"); these 3 mutant constructs were immersed in $\mathrm{PIP}_{2}$-containing bilayers, consistent with the experimental conditions under which their functional properties were assayed. The data from these computations are compared to results for the wild type hDAT simulated in $\mathrm{PIP}_{2}$-containing membranes we reported recently (30), and are analyzed utilizing the same protocols as described therein and detailed here in Methods.

\section{Different modes of interaction of the $N$-terminus with the rest of the hDAT protein correspond to differences in experimentally measured functional properties}

From the simulation trajectories we identified the regions of hDAT structure that interact with the N-terminus, and generated the per-residue contact map shown in Figure 1. This map shows that with $\mathrm{PIP}_{2}$ present in the membrane, the N-terminus, as a whole, interacts with all intracellular loop (IL) regions of hDAT (IL1, IL2, IL3, IL4, and IL5), and with the C-terminus. 

aCC-BY-NC-ND 4.0 International license.
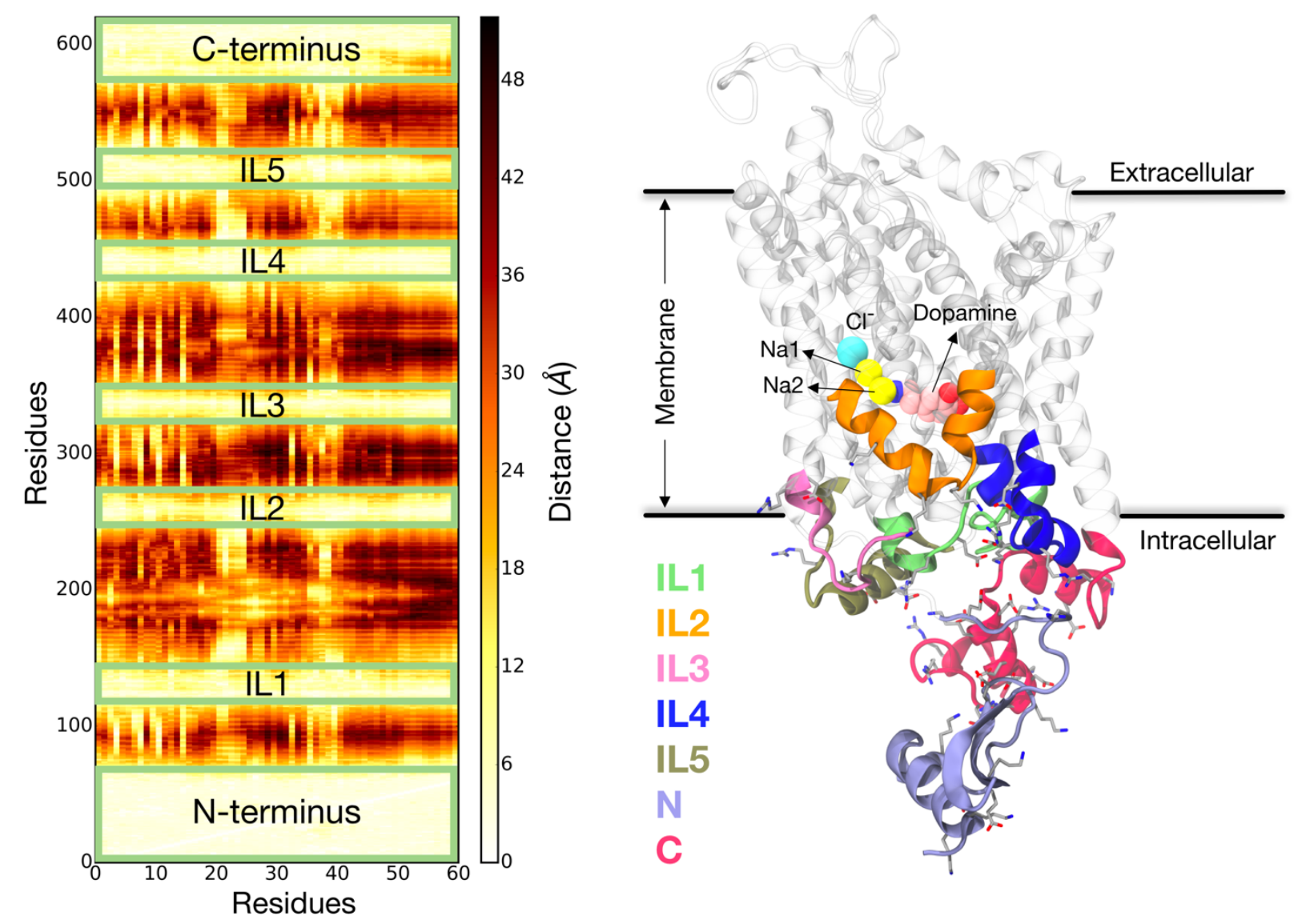

Figure 1. hDAT structure and N-terminus interactions. (Left) Contact map for interaction of $\mathrm{N}$-terminus residues (x-axis) with all hDAT residues (y-axis). Distance calculations were done with the closest-heavy algorithm implemented in MDTraj software (33). The color bar shows the minimum distance of each residue in the N-terminus to other residues (the lightest colored regions indicate the strongest interactions, e.g., in the various loop segments) as identified in the ensemble of $50 \mu \mathrm{s}$ trajectories for the wild-type hDAT embedded in the $\mathrm{PIP}_{2}$-containing lipid bilayer (see Methods). (Right) Snapshot of hDAT structure highlighting the intracellular segments interacting with the N-terminus in the ensemble of $50 \mu$ s trajectories. Charged residues are shown in licorice.

A detailed comparative analysis of the interactions between the N-terminus with the intracellular regions of wild type hDAT in $\mathrm{PIP}_{2}$-containing membranes (obtained from equivalent trajectories described recently (30)) and the constructs studied here (including PIP $_{2}$ depleted membrane conditions) reveals a specific pattern (modes) of interaction of the different parts of the N-terminus with intracellular regions of the transporter. These patterns are presented in Figure 2. 

aCC-BY-NC-ND 4.0 International license.

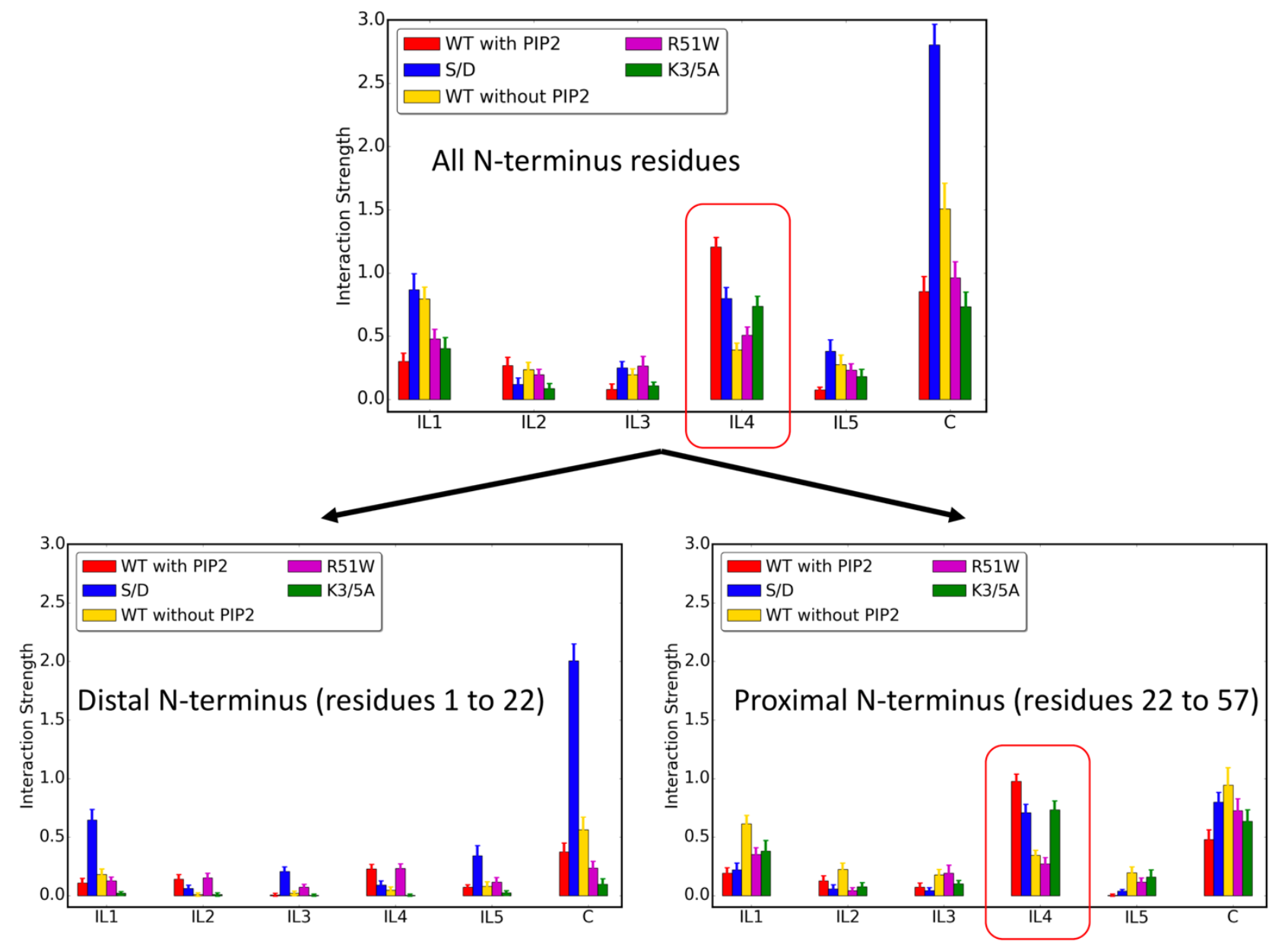

Figure 2. Modes of interaction of hDAT N-terminus with intracellular loop segments. The bars show the average interaction strength calculated from all 50 trajectories of every construct as described in Methods. Error bars show standard deviations (see Methods for full details of calculations and error estimation).

As part of experimental studies of reverse substrate transport (efflux) by DAT (22) and in SERT (34), their N-terminus was truncated, in the case of DAT eliminating the first 22 residues $(\Delta \mathrm{N} 22$ system). The measurements showed that the truncated transporters maintain direct substrate transport (uptake), but efflux is severely impaired. To compare with and interpret these experimental results, we calculated the modes of interaction of the various constructs for the corresponding components of the N-terminus: the distal $N$-terminus (residues 1 to 22), and the proximal $N$-terminus (residues 23 to 57). Results in Fig. 2 show a distinct difference between the interaction patterns of the two segments. Notably, the largest differences are registered for the interactions of these distal and proximal segments with IL1, IL4, and the C-terminus. A remarkable similarity is revealed between the pattern of interactions with IL4 calculated for the entire N-terminus, and for just the proximal N-terminus (cf. circled regions in Figure 2). This similarity is especially noteworthy because the interaction with IL4 has been singled out to be essential in the early steps of the substrate transport mechanism marked by the release of $\mathrm{Na}^{+}$ from the $\mathrm{Na} 2$ site (26). Thus, our finding here that the proximal $N$-terminus maintains the essential pattern of interaction with IL4 explains the surprising insensitivity of the inward substrate transport to the deletion of the first 22 residues. 
bioRxiv preprint doi: https://doi.org/10.1101/204164; this version posted January 30, 2018. The copyright holder for this preprint (which was not certified by peer review) is the author/funder, who has granted bioRxiv a license to display the preprint in perpetuity. It is made available under aCC-BY-NC-ND 4.0 International license.

The second largest difference between the interaction patterns of the proximal and distal $\mathrm{N}$-terminal segments evident in Figure 2 pertains to association with the C-terminus. In particular, the distal segment of the phosphomimic S/D construct has a remarkably high interaction quotient with the $\mathrm{C}$-terminus, whereas the weakest association with the $\mathrm{C}$-terminus is observed for the $\mathrm{K} 3 / 5 \mathrm{~A}$ construct (in fact, the distal segment of this double mutant $\mathrm{K} 3 \mathrm{~A} / \mathrm{K} 5 \mathrm{~A} \mathrm{~N}$ terminus is seen to engage in the least amount of interactions with any of the intracellular loops). This diametrically opposed characteristic of the interaction of the two constructs relative to the wild type is remarkable and is fully consistent with the experimentally determined functional properties compared to the wild type hDAT: (i)-only the S/D mutant construct in which the distal $\mathrm{N}$-terminus interacts strongly with the C-terminus, has been found thus far to be able to enhance dopamine efflux mediated by DAT in the absence of AMPH (22), (ii)-the K3/5A mutant, which we find to have the weakest interaction between the distal segment and the C-terminus, produces a very low amphetamine (AMPH)-induced dopamine efflux (32). The important relation of the distal segment with the efflux phenotype is underscored by the deleterious effect of the $(\Delta \mathrm{N} 22)$ truncation on efflux, but not on uptake, as discussed above.

\section{Multiple paths of inward release of $\mathrm{Na}^{+}$from the $\mathrm{Na} 2$ site are regulated by the modes of interaction of the N-terminus}

Our detailed study of the release of $\mathrm{Na}^{+}$from the $\mathrm{Na} 2$ site (termed $\mathrm{Na}+\mathrm{Na} 2$ release) which is known to initiate solute translocation by the $\operatorname{hDAT}(28,29)$ - has identified conformational changes related to function (CCRF), and the underlying allosteric mechanism $(30,35,36)$. These CCRF relate directly to the mode of interaction of the N-terminus with intracellular regions of the transporter in $\mathrm{PIP}_{2}$-containing membranes (30). In the earlier studies $(26,30)$ we showed that specific $\mathrm{PIP}_{2}$-mediated associations between the $\mathrm{N}$-terminus and various intracellular loop regions of DAT trigger conformational transitions related to the release of $\mathrm{Na}+/ \mathrm{Na} 2$. Here we find, from the new sets of MD simulations of the mutant constructs and conditions we study, that while they differ in their modes of N-terminus interactions (Figure 2), $\mathrm{Na}+/ \mathrm{Na} 2$ release is observed, albeit at different rates, during simulations of the same time length for various (Figures S1 to S4). While the rates of release events observed in the 50 trajectory ensembles for each construct/condition (see Figures S1 to S4) are not rigorously comparable to each other in a statistically meaningful manner, the prediction of inward release of $\mathrm{Na}+\mathrm{Na} 2$ in each of these constructs is consistent with experimental results and with our previous finding (30) that the destabilization of the $\mathrm{Na}+\mathrm{Na} 2$ is highly correlated with the amount of water penetration to the binding site (Table S4). Figures S5, S6, and S7 show details of the spontaneous release dynamics calculated for the R51W hDAT (Figure S5), the S/D system (Figure S6), and the no-PIP 2 system (Figure S7). The K3/5A mutant did not exhibit a release event, but the pattern of $\mathrm{Na}+/ \mathrm{Na} 2$ destabilization and intracellular gate opening is similar to that observed for S/D (Figures S3, S4, S8) suggesting that it is on the path to $\mathrm{Na}+/ \mathrm{Na} 2$ release as well.

These results for the large number of different constructs and conditions are remarkably consistent with the experimental evidence showing that the regular transport of the dopamine substrate (uptake) is affected differently by the various mutations/conditions than the reverse transport of this substrate (efflux) induced by amphetamine. Thus, efflux is impaired by most of these mutations/conditions, with the exception of the S/D system which exhibits dopamine efflux even in the absence of AMPH but under elevated intracellular $\mathrm{Na}^{+}$concentrations (25). In particular, experimental evidence points to the importance of $\mathrm{PIP}_{2}$-containing membranes for 
bioRxiv preprint doi: https://doi.org/10.1101/204164; this version posted January 30, 2018. The copyright holder for this preprint (which was not certified by peer review) is the author/funder, who has granted bioRxiv a license to display the preprint in perpetuity. It is made available under aCC-BY-NC-ND 4.0 International license.

various functional phenotypes of hDAT, including AMPH-induced efflux, but shows that substrate transport is only mildly affected if $\mathrm{PIP}_{2}$ content is reduced $(32,34,37)$.

The dependence of functional properties of the eukaryotic transporters on $\mathrm{PIP}_{2}$ is not shared by the bacterial transporter homologs, such as the structural prototype LeuT $(16,38)$, which do not require $\mathrm{PIP}_{2}$-containing membranes for transport and are also not exhibiting reverse transport. We reasoned that comparing molecular details of functional mechanisms involving the $\mathrm{N}$-terminus in the presence and absence of $\mathrm{PIP}_{2}$ would shed new light on the role introduced in evolution by the long N-terminus of the eukaryotic transporters. To discern the source of underlying mechanistic differences that connect $\mathrm{PIP}_{2}$ sensitivity to the long $\mathrm{N}$-terminus it became necessary, therefore, to understand (i)-how the initiating step of substrate transport, i.e., the release of $\mathrm{Na}+/ \mathrm{Na} 2$, is achieved in $\mathrm{PIP}_{2}$-containing vs $\mathrm{PIP}_{2}$-depleted membranes, and (ii)-what the role of the $\mathrm{N}$-terminus interactions is in the CCRF (including $\mathrm{Na}+/ \mathrm{Na} 2$ release process) when $\mathrm{PIP}_{2}$ is not present. To this end we used the MSM analysis to obtain a kinetic model for the $\mathrm{Na}+/ \mathrm{Na} 2$ release process in the no-PIP 2 system, as the comparison of quantitative terms for the wild type protein with/without $\mathrm{PIP}_{2}$ allows robust mechanistic inferences as illustrated below.

Markov State Model analysis of $\mathrm{Na}+\mathrm{Na} 2$ release in PIP $\mathrm{P}_{2}$-depleted membranes: To enable direct comparison of the results with the MSM analysis of wild type hDAT in $\mathrm{PIP}_{2}$ containing membranes (30) we built and analyzed the MSM for the no-PIP 2 system following the same protocol (see Methods and ref. (30)). Thus, as the same mechanism was followed in the two compared conditions (i.e., with/without $\mathrm{PIP}_{2}$ ), the same set of parameters as before (30) (Table S3) was used to generate the reduced conformational space with the tICA method (see Methods). The tICA energy landscape (Figure 3B) was obtained by projecting all the conformations from all the trajectories onto the first two tICA reaction coordinates. Visualization of conformations belonging to different regions of the tICA energy landscape revealed that this landscape, unlike the one for $\mathrm{PIP}_{2}$-containing membrane conditions (shown in Figure $3 \mathrm{~A}$ ), could be divided into only two (rather than three) regions in terms of the location of the $\mathrm{Na}+\mathrm{Na} 2$ ion: one in which the $\mathrm{Na}+/ \mathrm{Na} 2$ is still bound in the $\mathrm{Na} 2$ site, and the other in which the $\mathrm{Na}+\mathrm{Na} 2$ is already released (Figure 3B). Thus, this tICA space (Figure 3B) does not contain a region representing the intermediate state seen in the wild type hDAT system in PIP2-enriched membranes when the $\mathrm{Na}+/ \mathrm{Na} 2$ has left the binding site but is not yet released to the intracellular environment because it is interacting with the E428 side chain (Figure 3C). Because this interaction requires the E428 side chain to be free from its partner in the E428-R445 gate (30), the results suggest that a change in N-terminus interactions due to $\mathrm{PIP}_{2}$ depletion directly affects this gate. Indeed, the finding summarized in Fig. 2 shows a major reduction in the interactions of the N-terminus with IL4 in the absence of PIP ${ }_{2}$, which is thus seen to result in a more stable R445-E428 gate in the absence of $\mathrm{PIP}_{2}$ (Figure 3D, see also Figure S9). 
bioRxiv preprint doi: https://doi.org/10.1101/204164; this version posted January 30, 2018. The copyright holder for this preprint (which was not certified by peer review) is the author/funder, who has granted bioRxiv a license to display the preprint in perpetuity. It is made available under aCC-BY-NC-ND 4.0 International license.

A

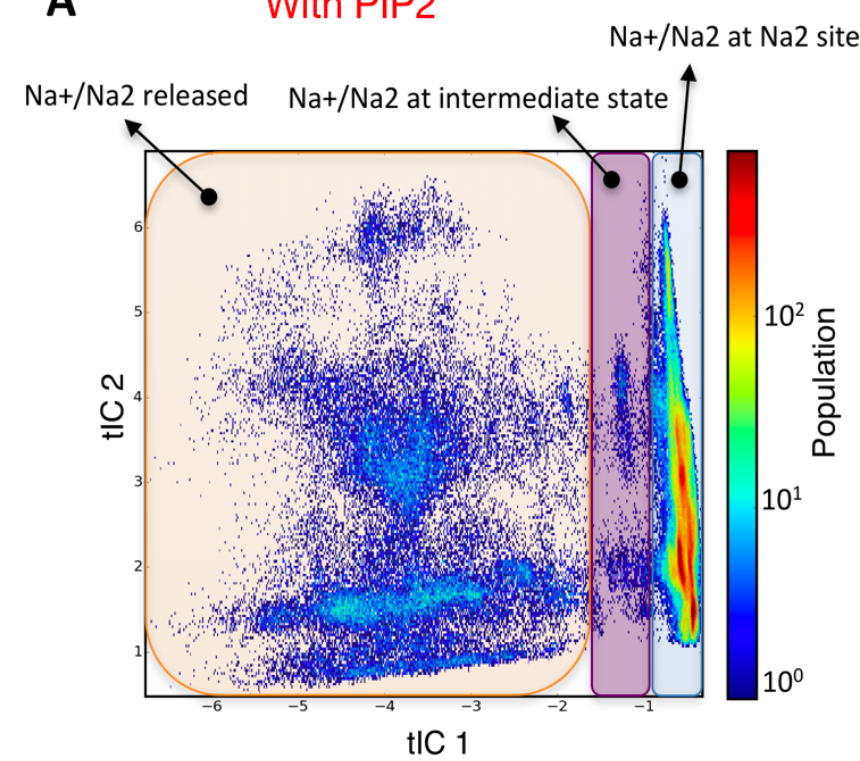

C intermediate state

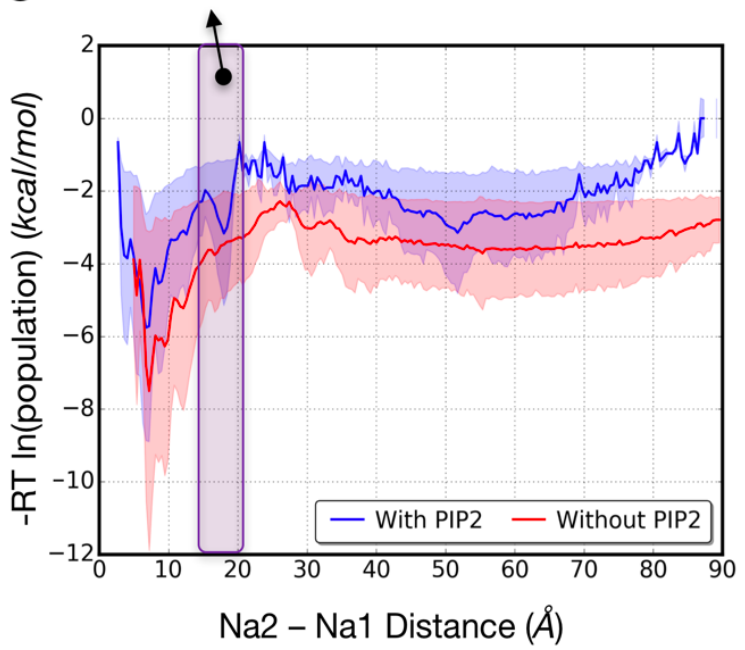

B

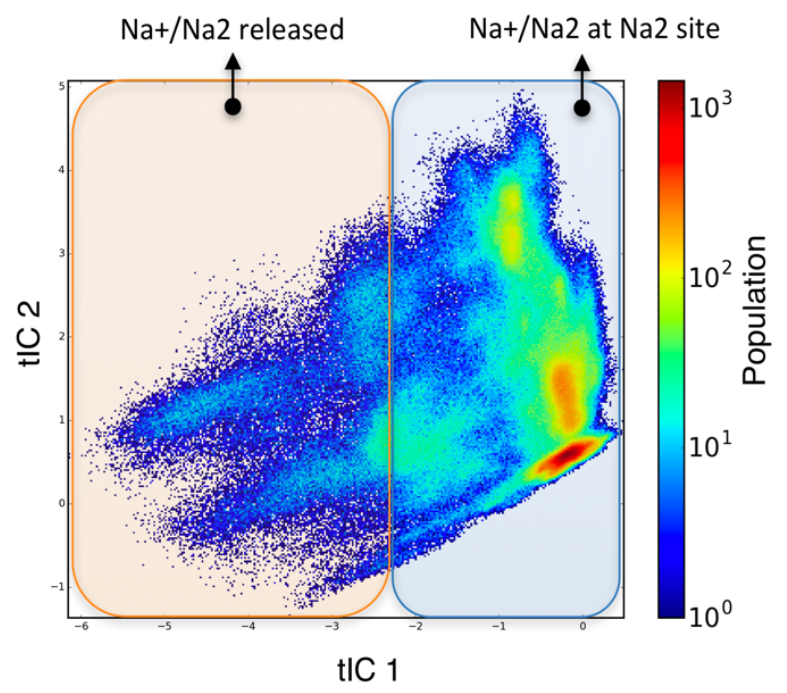

D

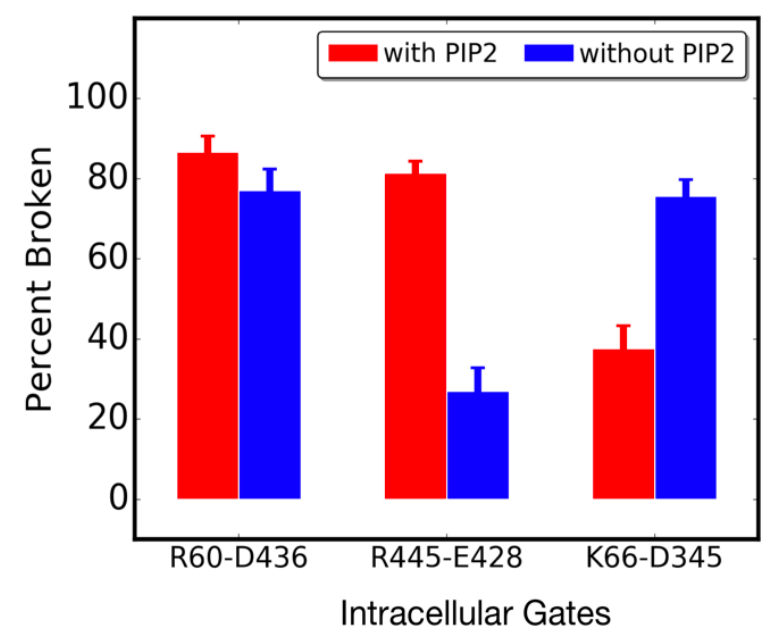

Figure 3. hDAT tICA space in presence and absence of PIP 2 lipids. (A and B) Populationweighted tICA landscape for hDAT trajectories in $\mathrm{PIP}_{2}$-containing membranes $(\mathrm{A})$ and for the no-PIP ${ }_{2}$ system (B). For each system, all of the conformations in all of the 50 trajectories are projected on the space of the tICA $1^{\text {st }}$ and $2^{\text {nd }}$ eigenvectors. Regions differing with respect to the location of $\mathrm{Na}+/ \mathrm{Na} 2$ are highlighted on the tICA landscape with transparent boxes of different colors. (C) All the conformations are projected on the reaction coordinate based on $\mathrm{Na}+/ \mathrm{Na} 2$ distance from the sodium at site $\mathrm{Na1}$, and the free energy $(\Delta \mathrm{G})$ is population-based and is calculated as $[\Delta \mathrm{G}=-\mathrm{RT} \ln$ (population)]. The intermediate state is highlighted by the magenta box; note the absence of a distinct minimum in the absence of PIP 2 (red line). Error bars (shown as transparent shades) are calculated using the bootstrap method on 100 blocks of frames with 160 ns time range that are randomly extracted from all 50 trajectories. (D) Comparing percent of broken interactions of intracellular gates in the control simulation ( $\mathrm{PIP}_{2}$-containing membrane) (red bars) and in the no-PIP 2 system (blue bars) averaged over all 50 trajectories of each construct. Error bars are calculated using the bootstrap method by randomly selecting 50 trajectories (with replacement) and repeating the process for 1000 iterations. 
bioRxiv preprint doi: https://doi.org/10.1101/204164; this version posted January 30,2018 . The copyright holder for this preprint (which was not certified by peer review) is the author/funder, who has granted bioRxiv a license to display the preprint in perpetuity. It is made available under aCC-BY-NC-ND 4.0 International license.

To build the MSM from the 2D tICA landscape shown in Fig. 3B, we followed the same protocol as before (30) to obtain the implied time scales plot (see Methods). As shown in Figure S10 (left panel), Markovian behavior of the system is observed after a lag time of $\sim 80 \mathrm{ns,}$ therefore the transition probability matrix (TPM) (see Methods) at $80 \mathrm{~ns}$ lag time was selected for all subsequent analyses of the no-PIP 2 system. Mapping all microstates on the tICA landscape and coloring them based on the first MSM eigenvector (i.e., the first TPM eigenvector, shown in Figure $\mathrm{S} 11$ ) reveals that $\mathrm{Na}+\mathrm{Na}$ is still bound in microstates with positive sign (red circles in Figure S11), whereas the microstates with negative sign (blue circles in the Figure S11) have released the $\mathrm{Na}+\mathrm{Na} 2$ to the intracellular environment. Since the state population flows from the positive to negative states, the first MSM eigenvector is seen to capture the overall release kinetics of the $\mathrm{Na}+\mathrm{Na} 2$. The implied time-scale equation (see Methods) shows that this relaxation mode is characterized by time-scales of $\sim 1.1 \mu \mathrm{s}$, comparable to the previously reported kinetics for hDAT in the $\mathrm{PIP}_{2}$-containing membranes ( $\left.800 \mathrm{~ns}\right)(30)$ (Figure $\left.\mathrm{S} 10\right)$.

To compare the mechanisms of sodium release from the Na2 site of the WT hDAT in $\mathrm{PIP}_{2}$-containing vs $\mathrm{PIP}_{2}$-depleted membranes, we used the same transition path theory (TPT) analysis (see Methods) to obtain the most probable release pathways of $\mathrm{Na}+\mathrm{Na} 2$, and quantified the flux associated with each of these on a macrostate-based MSM using 15 macrostates as before (30). Similar to the WT in $\mathrm{PIP}_{2}$-containing membranes, several pathways are revealed in the no-PIP 2 system. Here, the first 10 pathways identified by the TPT analysis contribute $\sim 80 \%$ of the total flux between $\mathrm{Na}+/ \mathrm{Na} 2$ bound states and $\mathrm{Na}+/ \mathrm{Na} 2$ released states (highlighted in Figure 4; see Table S5 for quantification of fluxes). Their structural context is shown in Figure 4 and Figure S13.

The identification of the major $\mathrm{Na}+\mathrm{Na} 2$ release pathway in the no- $\mathrm{PIP}_{2}$ system reveals a clear difference from the release in the $\mathrm{PIP}_{2}$-enriched system (cf. panels labeled "with $\mathrm{PIP}_{2}$ " and "without PIP 2 " in Figure 4) that echoes the difference in the modes of interaction described by the results in Fig. 2. In the no-PIP 2 system, the first major pathway for the release contributes $\sim 40 \%$ of the total flux and is formed when both the R60-D436 and the E428-R445 gates remain closed (a consequence of the much lower interaction with IL4 as seen in Fig. 2), but the K66D345 is open (highlighted in the transparent red box in Figure 4). This is in sharp contrast to the result in the presence of $\mathrm{PIP}_{2}$ where this pathway is a minor contributor to the total flux, at only $\sim 13 \%$.

The second major pathway in the no-PIP 2 system is enabled when both R60-D436 and E428-R445 gates are broken, but R60 is now able to form interactions with E428 (Figure 4, green box). This pathway contributes $\sim 32 \%$ to the total flux. Notably, this was the major $\mathrm{Na}+/ \mathrm{Na} 2$ release pathway in the presence of $\mathrm{PIP}_{2}$, contributing about $48 \%$ percent of the total flux. But because in the absence of $\mathrm{PIP}_{2} \mathrm{R} 60$ (or R445) is interacting with E428, the intermediate state cannot form.

The third major pathway in the no-PIP 2 system is formed when the R60-D436 gate is broken and the N-terminus moves closer to IL2. The intracellular gate interaction E428-R445 is still maintained (Figure 4, blue box). In the presence of $\mathrm{PIP}_{2}$, this pathway contributes about $\sim 39 \%$ to the total flux, but in the no-PIP 2 system the contribution is reduced to $28 \%$. Importantly, a major difference is that in the presence of $\mathrm{PIP}_{2}, \mathrm{R} 60$ is seen to be engaged in $\mathrm{PIP}_{2}$-mediated interactions with several positively charged residues from IL2 (K257, K260, K264), whereas in the no-PIP 2 system the association between the N-terminus and the IL2 region still permits interactions between R60 and D68 and/or D385 (see macrostate 3 in Fig. 4 and Fig. S12). 
bioRxiv preprint doi: https://doi.org/10.1101/204164; this version posted January 30, 2018. The copyright holder for this preprint (which was not certified by peer review) is the author/funder, who has granted bioRxiv a license to display the preprint in perpetuity. It is made available under aCC-BY-NC-ND 4.0 International license.

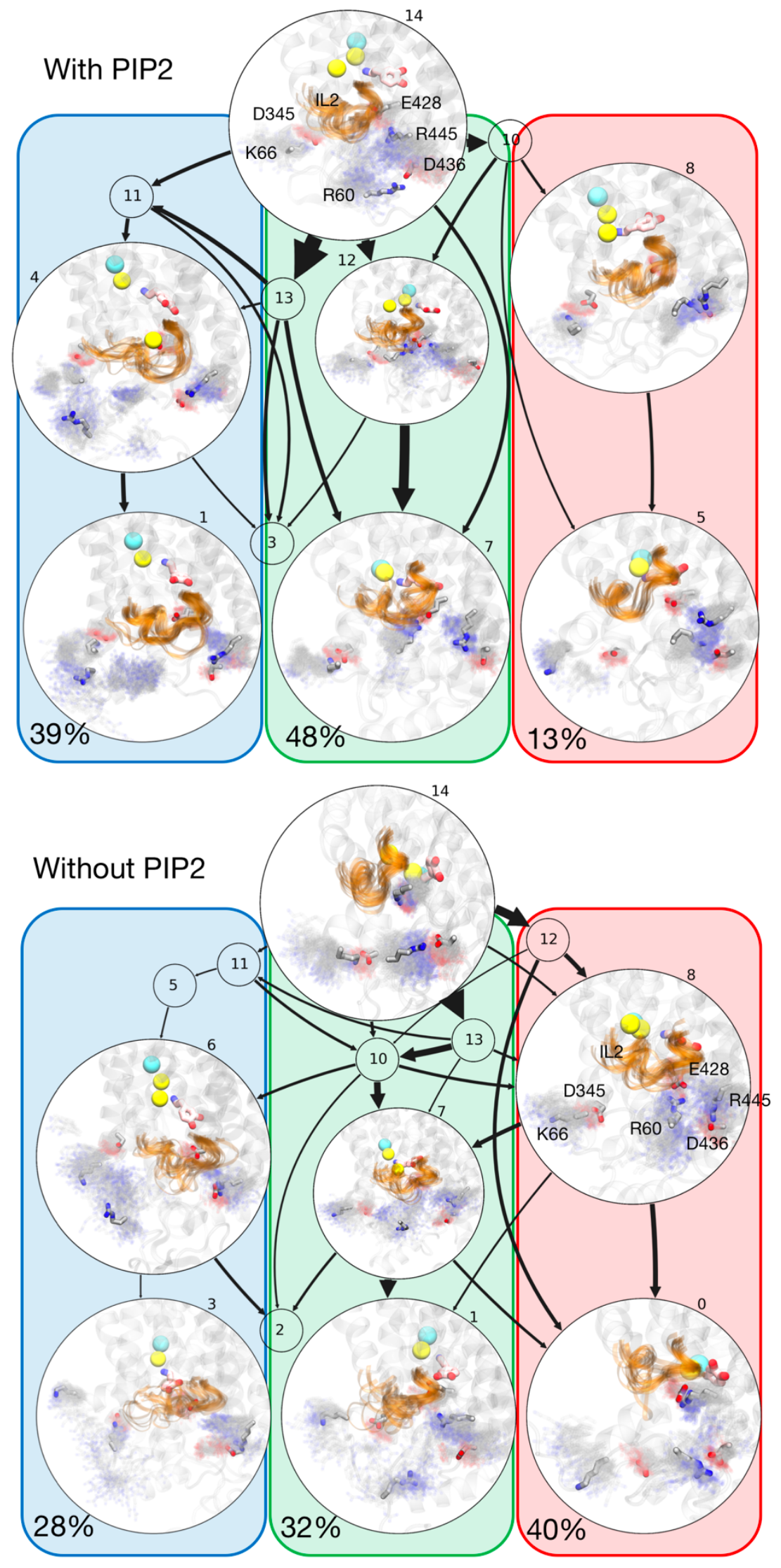

Figure 4. Comparison of $\mathrm{Na}+/ \mathrm{Na} 2$ release pathways calculated in $\mathrm{PIP}_{2}$-enriched and $\mathrm{PIP}_{2}$ depleted membranes. Results from the transition path theory (TPT) analysis for the release of 
bioRxiv preprint doi: https://doi.org/10.1101/204164; this version posted January 30, 2018. The copyright holder for this preprint (which was not certified by peer review) is the author/funder, who has granted bioRxiv a license to display the preprint in perpetuity. It is made available under aCC-BY-NC-ND 4.0 International license.

$\mathrm{Na}+\mathrm{Na} 2$ to the intracellular environment by the wild-type hDAT in $\mathrm{PIP}_{2}$-containing membranes (top) and in $\mathrm{PIP}_{2}$-depleted membranes (bottom) systems. Arrow thickness represents relative flux magnitude for each transition. A representative conformation is shown for selected macrostates, with IL2 highlighted in orange (cartoon representation) on the transparent structure of hDAT. Density representation of the residues forming intracellular gates are shown as fuzzy background gray colors and the most probable locations of these residues within the density representation are highlighted in licorice rendering and labeled for reference. Dopamine is shown in pink licorice and sodium and chloride ions in yellow and cyan spheres, respectively. Red, green, and blue boxes highlight the three major release pathways of $\mathrm{Na}+\mathrm{Na} 2$; numbers indicate the fraction of the total flux carried by each major pathway.

Overall, the TPT analysis shows that the preference ranking of the various release pathways, which we quantified by calculating fluxes, is strongly affected by the $\mathrm{PIP}_{2}$ lipids in a manner consistent with the modes of interaction with the N-terminus. The difference in $\mathrm{Na}+\mathrm{Na} 2$ mechanism between the two conditions (with/without $\mathrm{PIP}_{2}$ ) is underscored by the finding that the increased dynamics of the N-terminus (Figure S12) in the absence of $\mathrm{PIP}_{2}$ results in a destabilization of the K66-D345 gate, which enhances the $\mathrm{Na}+\mathrm{Na} 2$ release flux through a pathway that was only marginally active in the presence of $\mathrm{PIP}_{2}$ (pathway highlighted in red box). Taken together, these results show how the eukaryotic transporters can adapt to different membrane composition conditions by utilizing different $\mathrm{N}$-terminus interaction patterns so that release of the $\mathrm{Na}^{+}$from the $\mathrm{Na} 2$ site is maintained.

\section{Discussion}

The extensive investigations of the molecular mechanisms underlying the vital role of human DAT in signal transduction have profited much from the availability of structurally simpler prototypes of the NSS, such as the bacterial analog LeuT (a leucine and alanine transporter), for which the crystallographic data provided the first structural basis for detailed molecular studies (see $(16,38)$ ). When the striking fold-similarity of LeuT to the eukaryotic and human neurotransmitter transporters such as DAT was established $(39,40)$, it enabled the major progress in understanding the functional mechanism documented in a very large number of publications (for reviews see (41)). It became clear, however, that various physiologically important mechanisms that eukaryotic transporters such as DAT and SERT have acquired through evolution involve allosteric coupling to their environment that differentiate them from the structurally simpler bacterial analogs. In a large number of studies $(20,22,24-26,30,32,42-51)$ to which we have contributed findings from both computation and experiments, these new functions of the eukaryotic transporters - such as regulation by lipids, by phosphorylation, and the observed efflux phenotype - were shown to be mechanistically modulated by defined structural elements, especially the relatively long $\mathrm{N}$ - and $\mathrm{C}$-terminal segments that are found exclusively in this class, and not in bacterial counterparts (40). These intracellularly located Nand C-terminal segments are the most divergent structural units within the NSS family of proteins, as they range in size from just a few $(\sim 10)$ amino acids (in bacterial members, such as LeuT) to segments containing $>60$ residues (N-terminus of eukaryotic NSS such as DAT, SERT, see $(40,52))$.

To understand how the new functions of the eukaryotic transporters relate to the presence of the N-terminus and its dynamic properties, we quantified the interaction of the hDAT Nterminus with the intracellular regions of the hDAT transporter. On this basis we were able to relate different modes of interaction to the functional mechanisms of DAT through the relation 
bioRxiv preprint doi: https://doi.org/10.1101/204164; this version posted January 30, 2018. The copyright holder for this preprint (which was not certified by peer review) is the author/funder, who has granted bioRxiv a license to display the preprint in perpetuity. It is made available under aCC-BY-NC-ND 4.0 International license.

between the experimentally measured effects of mutations/conditions, and the changes in modes of interaction. The release of the $\mathrm{Na}^{+}$ion from the $\mathrm{Na} 2$ site, which is known to be a key first step in the substrate translocation cycle $(28,29)$, served as an established functional readout for the initiation of the transport cycle. We showed how the effects of modes of interaction of the Nterminus with various intracellular regions of the transporter relate to various modes of intracellular gate opening and paths of water penetration. This led to a mechanistic interpretation of the experimentally measured modifications of the functional properties observed for mutant constructs in the presence and absence of $\mathrm{PIP}_{2}$. Together, our results reveal how changes in the modes of interaction stemming from N-terminus mutations and $\mathrm{PIP}_{2}$ depletion, are directly associated with stabilization/destabilization of intracellular gates, and their effect on the penetration of water into the binding site (Figure 5A) that is required for uptake and efflux in hDAT.

By specifying the modes of interactions of the N-terminus that regulate the opening probabilities of water pathways separately for the distal and the proximal segments of the Nterminus, our findings provide a clear mechanistic explanation for a persistent conundrum in the literature regarding the effects of (i)-truncating the first 22 residues of the N-terminus, and (ii)$\mathrm{PIP}_{2}$ depletion, and in particular their different effects on the uptake and efflux aspects of eukaryotic transporter function. That the truncation has little effect on uptake is explained by our finding (summarized in Figure 2) that the pattern of interactions of the N-terminus with IL4 of DAT is mimicked by just the proximal segment, without special involvement of the distal segment. However, this interaction that has been shown to disrupt the E428-R445 gate and thus serve as one of the major mechanistic triggers for $\mathrm{Na}+\mathrm{Na} 2$ release, is $\mathrm{PIP}_{2}$-mediated (26), and is reduced under no-PIP 2 conditions (Figure 2). This might have suggested a reduced release of $\mathrm{Na}+/ \mathrm{Na} 2$ that would impair the substrate uptake function under these conditions. Yet this is not what is observed experimentally, as the uptake function of hDAT is not impaired by PIP $_{2}$ depletion from the membrane. The mechanistic explanation emerges from our analysis of (a)-the simulations presented here that show how modes of interaction of the N-terminus change under the different conditions (and for the various mutant constructs; Figure 2), and (b)-the MSM from the simulation trajectories of the no-PIP 2 condition showing how $\mathrm{Na}+/ \mathrm{Na} 2$ release is maintained, but with different probabilities of the release pathways that involve alternative water penetration channels (e.g., the TM1a/IL3 channel (Figure 5A) that is formed when K66-D345 interaction breaks).

The effect of N-terminus truncation on efflux is even more interesting in the context of the functional difference between the bacterial and eukaryotic transporters because elimination of the distal segment in the neurotransmitter SLC6 transporters impairs a function not shared with the bacterial homologs. The relation of the distal segment to efflux makes it tempting to speculate that some combination of the interaction modes of the proximal N-terminus (Figure $5 \mathrm{~B}$ ) is required for efflux. Indeed, the results summarized in Figure 2 show (i)-a reduction of proximal N-terminus/IL4 interactions in constructs with low efflux activity (R51W and K3/5A) and in $\mathrm{PIP}_{2}$-depleted membranes, and (ii)-a reduction in distal $\mathrm{N}$-terminus/C-terminus interactions in the efflux-deficient $\mathrm{K} 3 / 5 \mathrm{~A}$ mutant, and an increase of these interactions in the efflux-promoting S/D construct. An involvement of the distal N-terminus/C-terminus interactions in facilitating efflux is also consistent with the observation that palmitoylation of the $\mathrm{C}$-terminus reduces efflux, presumably by limiting interaction with the $\mathrm{C}$-terminus. This limitation would reduce $\mathrm{N}$-terminus phosphorylation $(53,54)$ by the $\mathrm{Ca} 2+$ /calmodulin-dependent protein kinase II (CaMKII) that is proposed to attach to the distal C-terminus of hDAT in order to phosphorylate the serine residues in the distal N-terminus for AMPH-induced efflux (25). 
bioRxiv preprint doi: https://doi.org/101101/204164; this version posted January 30,2018 . The copyright holder for this preprint (which was not certified by peer review) is the author/funder, who has granted bioRxiv a license to display the preprint in perpetuity. It is made available under aCC-BY-NC-ND 4.0 International license.

The mechanistic explanations for the experimental findings about the modulation of function by the N-terminus of DAT, SERT, and other eukaryotic transporters, connect the elongation of $\mathrm{N}$ - and $\mathrm{C}$-termini in the evolution from bacterial homologs, with the appearance of new functional properties (e.g., efflux). These functional phenotypes, enabled by specific roles of the proximal and distal segments, are not shared by the bacterial homologs which lack the long N-terminus but share the overall molecular architecture (termed the "LeuT-fold"; (38)). The specific (different) involvement of the proximal and distal segments - such as the role of the proximal segment in sustaining transport in $\mathrm{PIP}_{2}$-depleted membranes, and of the distal segment in modulating efflux - may represent an evolutionary adaptation required for the function of eukaryotic transporters expressed in various cell types of the same organism that differ in the lipid composition and protein complement of the membrane environment.

A

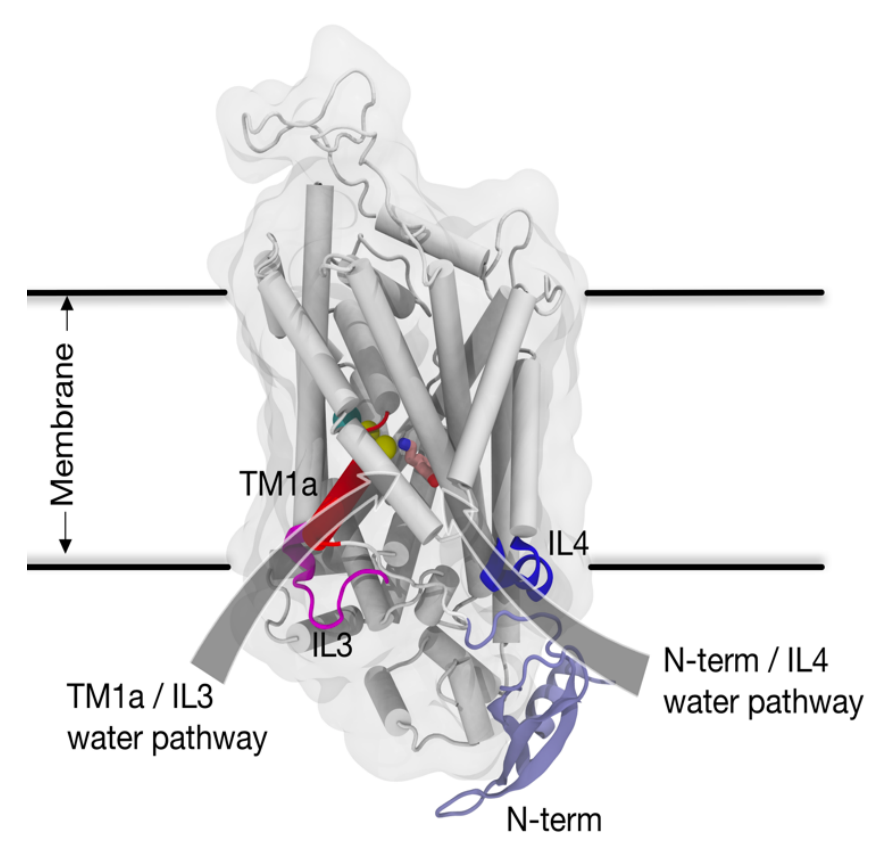

B

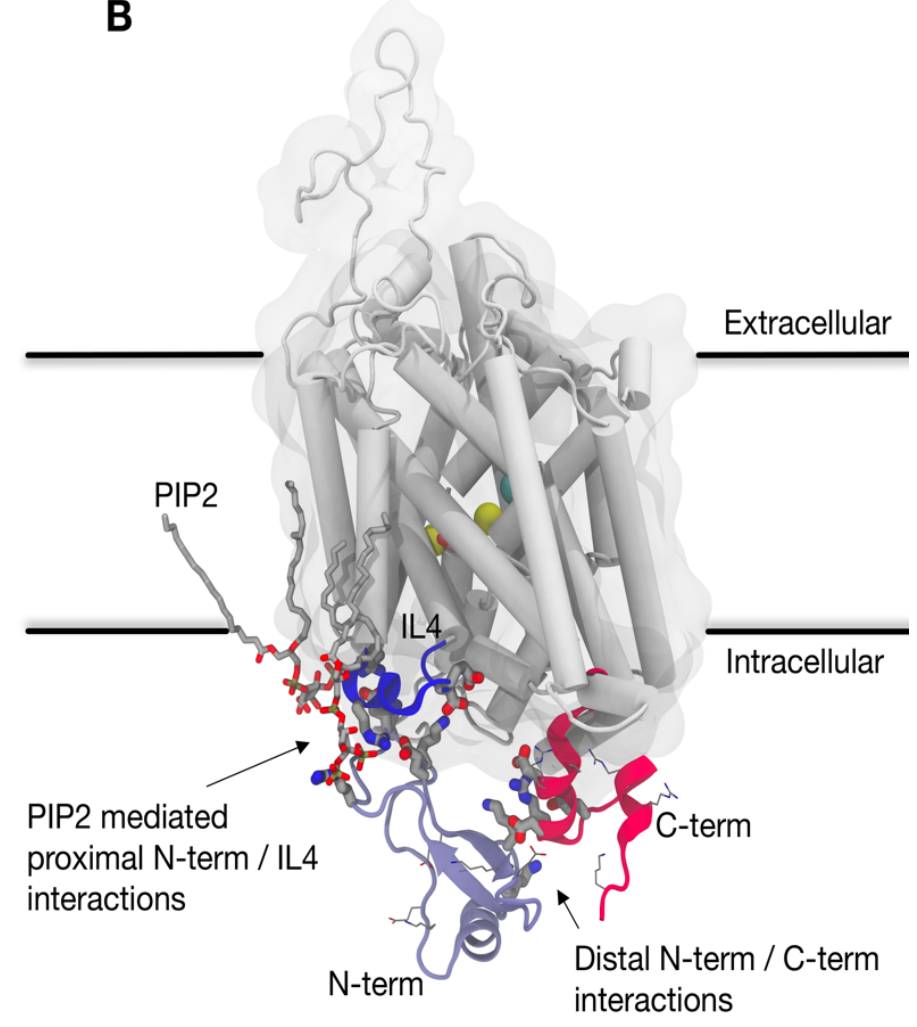

Figure 5. Illustration of effects of different modes of $\mathrm{N}$-terminus interactions on functional phenotypes. (A) Representation of two water penetration pathways from the intracellular side of the hDAT. The N-terminus/IL4 water pathway is the main water penetration path in the wildtype in the presence of $\mathrm{PIP}_{2}$ lipids. In the absence of $\mathrm{PIP}_{2}$, the N-terminus/IL4 water (blue) penetration pathway is impaired, and hydration of the binding site is achieved primarily through another water pathway formed between TM1a and IL3 (red). (B) Representation of conditions linked to the efflux function of hDAT. The interaction of the proximal N-terminus with IL4 (blue) is mediated by $\mathrm{PIP}_{2}$ lipids, and the distal part of the N-terminus engages with the $\mathrm{C}$ terminus (red). All charged residues are shown for both $\mathrm{N}$-terminus and $\mathrm{C}$-terminus with thin licorice; charged residues engaged in interactions between N-terminus and either IL4 or the C- 
bioRxiv preprint doi: https://doi.org/10.1101/204164; this version posted January 30,2018 . The copyright holder for this preprint (which was not certified by peer review) is the author/funder, who has granted bioRxiv a license to display the preprint in perpetuity. It is made available under aCC-BY-NC-ND 4.0 International license.

terminus, are highlighted with thick licorice. Dopamine is shown in the S1 binding site (in pink), sodium ions are shown as yellow spheres, and the chloride ion is in cyan.

\section{Methods}

System preparation. The molecular model of full-length wild type hDAT used in this study is the same as described and investigated earlier (30). The R51W and $\mathrm{K} 3 \mathrm{~A}+\mathrm{K} 5 \mathrm{~A}$ constructs were prepared by introducing the mutations in the wild type hDAT model using VMD mutator plugin (55). To build the S/D mutant (simultaneous mutations of S2, S4, S7, S12, and S13 residues to Asp), we combined, using Modeller version 9v1 (56), the 57-620 residue stretch from the wild type hDAT structure with the structural model of the 1-57 S/D segment elaborated and described previously (20).

The full length models of the hDAT constructs R51W, K3A+K5A (heretofore referred to as "K3/5A"), and S/D were inserted into the same pre-equilibrated compositionally asymmetric bilayer membrane used for MD simulations of the wild type hDAT (30). This lipid bilayer was designed to mimic a neuronal cell plasma membrane and contains $5 \% \mathrm{PI}(4,5) \mathrm{P}_{2}$ lipid on the intracellular leaflet of the bilayer (see Table $\mathrm{S} 1$ for membrane lipid composition). For the simulations of the wild type hDAT in $\mathrm{PI}(4,5) \mathrm{P}_{2}$-depleted membrane environment, as done previously (26), all the $\mathrm{PI}(4,5) \mathrm{P}_{2}$ lipids in the bilayer were changed to POPE lipids, the major component of the intracellular leaflet of our model bilayer. All the hDAT-membrane systems were solvated in a $150 \mathrm{mM} \mathrm{K}^{+} \mathrm{Cl}^{-} \mathrm{TIP} 3 \mathrm{P}$ water solution with ions added for neutrality, resulting in a final atom count of $\sim 150,000$.

Molecular dynamics simulations. All-atom molecular dynamics (MD) simulations were carried out using the same scheme as described earlier for the wild type hDAT in PI(4,5) $\mathrm{P}_{2}$-enriched membranes (30). Briefly, using NAMD software version 2.10 (57), the systems first were equilibrated following the same multi-step equilibration protocol used previously (30) during which the backbone of the protein was first fixed, then harmonically restrained, and finally released. After this equilibration phase, the velocities of all the atoms in the system were reset (at $\mathrm{T}=310 \mathrm{~K}$ using random number seed) and 50 independent $\sim 1 \mu \mathrm{s}$ long unbiased MD simulations were carried out using the latest version of the ACEMD software (58) resulting in a cumulative MD simulation time of $\sim 50 \mu$ s per system. These production simulations were performed under NVT ensemble and with all the default run parameters validated by the ACEMD developers (https://www.acellera.com/) and in a large number of published applications (e.g., see https://www.acellera.com/products/molecular-dynamics-software-GPU-acemd/use-cases/). The run parameters (4fs time step with hydrogen mass repartitioning; PME for electrostatics; switched Lennard-Jones interactions with a cut-off of $9 \AA \AA$, and switching distance set to $7.5 \AA \AA$ ) have been shown to reliably reproduce known values for free energy of protein folding and a variety of properties of lipid membranes $(59,60)$. In addition, ensemble MD simulations with ACEMD have been generally used to generate large data sets of trajectories for quantitative analysis of kinetics of ligand-induced conformational transitions in $\mathrm{G}$ protein-coupled receptors (GPCRs) (61), of protein-protein association/dissociation processes (62), of phospholipid scrambling process mediated by the GPCR opsin (63) as well as for identifying pathways for spontaneous cholesterol movement in adenosine A2A GPCR (64).

Calculation of the interaction strengths. To obtain a measure of interaction between Nterminus and other intracellular regions of hDAT we counted the number of interactions between charged residues from the $\mathrm{N}$-terminus and the intracellular loop regions. The number of 
bioRxiv preprint doi: https://doi.org/10.1101/204164; this version posted January 30, 2018. The copyright holder for this preprint (which was not certified by peer review) is the author/funder, who has granted bioRxiv a license to display the preprint in perpetuity. It is made available under aCC-BY-NC-ND 4.0 International license.

interactions was quantified for a cutoff distance of $7 \AA$ between interacting residue pairs from head group atoms of the N-terminus and of intracellular domain residues (using $\mathrm{N}_{\xi}$ for Lys, $\mathrm{C}_{\xi}$ for $\mathrm{Arg}, \mathrm{C}_{\delta}$ for $\mathrm{Glu}$, and $\mathrm{C}_{\gamma}$ for Asp). The residues included in the calculations are listed in Table S2. All 50 trajectories for each construct were used for these calculations, with the first $500 \mathrm{~ns}$ of each trajectory considered an equilibration phase so that only the 500-940 ns time interval from each trajectory was used to ensure that the total number of frames used for the analysis is the same for each construct. Total number of interactions is then divided by total number of trajectories (i.e. 50) to obtain the average "interaction strength" represented in Figure 2. Error bars are calculated by taking the standard deviation of "interaction strength" in all 50 trajectories.

Markov State based quantitative kinetic model construction. We used the Markov State Model (MSM) approach to analyze the trajectories in the absence of $\mathrm{PIP}_{2}$ lipids and build quantitative kinetic models of sodium release from the $\mathrm{Na} 2$ site for comparison with the kinetics and pathways calculated in the presence of $\mathrm{PIP}_{2}$ in Ref. (30). Therefore, we have followed here the same protocol as described in detail in Ref. (30). Such quantitative kinetic models provided by Markov State Models (MSMs) $(65,66) \cdot(67)$ have been widely applied in protein folding studies $(68,69)$ and MSM based kinetic models predictions have been validated experimentally (70,71). We and others have used MSMs combined with reactive flux analysis, such as transition path theory (TPT) analysis to obtain key mechanistic insights into functions of membrane proteins $(30,72,73)$. The three main components for achieving quantitative MSM-based kinetic models are briefly reviewed below.

1. Dimensionality reduction using $t I C A$. Reducing the dimensionality of a system as large and complex as the membrane-immersed hDAT is necessary in order to construct an interpretable kinetic model. A natural choice of suitable reaction coordinates is for those that can project the conformational space of the system along its slowest reaction coordinate, as this reaction coordinate will capture most of the conformational heterogeneity during the time-course of the simulation (74). The time-structure based Independent Component Analysis (tICA) method was developed recently for this purpose of capturing the slowest reaction coordinate of a system (7577). Briefly, the tICA method involves a transformation that utilizes two matrices constructed from the trajectory data: the covariance matrix $\mathbf{C}$, and a time-lagged covariance matrix $\boldsymbol{C}_{\boldsymbol{T} L}$. The slowest reaction coordinates of a system are then defined by eigenvectors of the generalized eigenvalue problem: $\boldsymbol{C}_{\boldsymbol{T} L} \mathbf{V}=\mathbf{C V} \boldsymbol{\Lambda}$, where $\boldsymbol{\Lambda}$ and $\mathbf{V}$ are the eigenvalue and eigenvector matrices, respectively. The eigenvectors corresponding to the largest eigenvalues identify the slowest reaction coordinates. Here we used a lag time of $16 \mathrm{~ns}$ to construct the time-lagged covariance matrix $\boldsymbol{C}_{\boldsymbol{T} \boldsymbol{L}}$, and the tICA parameters were chosen as before for the hDAT molecular system (30), to measure a) the dynamics of the $\mathrm{Na}^{+}$ion from the $\mathrm{Na} 2$ site, termed $\mathrm{Na}+/ \mathrm{Na} 2$, and b) the dynamics of intracellular gates formed between residues R60, D436, R445, E428 (Table S3).

2. Markov Model construction. The conformational transitions of biomolecular systems where the time between transitions is long enough can be modeled as Markov chains (65) in which transitions among states depend only on the current state of the system (i.e., Markovian behavior). Such Markov models provide powerful tools for outcome prediction by enabling the extraction of long time-scale information from multiples of short time-scale events.

Two components needed for the construction of such a Markov model are: an ensemble of microstates of the system, and of the transitions among these microstates (78). Microstates are defined by clustering the conformational space of the system into several basins using automated clustering algorithms like $K$-means or $K$-centers, and is most practical if performed in a dimensionality-reduced space such as the one obtained from the tICA transformation. The transitions among the microstates are calculated for a particular time interval between each of the 
transitions (so called lag-time) and stored in the transition count matrix. By row-normalizing the transition count matrix one obtains the transition probability matrix (TPM). To validate Markovian behavior, the TPMs are constructed for multiple lag times and the relaxation timescales of the system are extracted by using the relation:

$$
\tau_{i}=-\frac{\tau^{\prime}}{\ln \lambda_{i}}
$$

where $\tau$ 'is the lag-time used for building the TPM, $\lambda_{\mathrm{i}}$ is the $i^{\text {th }}$ eigenvalue of the transition probability matrix, and the resulting $\tau_{i}$ is the so-called implied timescale corresponding to the $i^{\text {th }}$ relaxation mode of the system. The system is considered to be Markovian if the behavior is such that $\tau_{i}$ is independent of $\tau^{\prime}$; the corresponding TPM is a Markovian TPM that contains all the information about the thermodynamics and kinetics of the system. Thermodynamic information is stored in the first eigenvector (which has an eigenvalue of 1). Information about kinetics is stored in the subsequent (second, third, etc.) eigenvectors, with the second eigenvector (corresponding to the second largest eigenvalue) capturing the slowest dynamics of the system, the third eigenvector capturing the second slowest dynamics, and so on.

Following the same protocols as described in detail in Ref. (30) for the construction of the Markov Models we discretized the reduced conformational space generated by the first two tICA reactions coordinates into 100 microstates (Figure S11) using the K-means clustering algorithm implemented in the MSMBuilder3 software (79). Transition probability matrices (TPMs) were constructed at several different lag times to obtain the implied time-scale plots shown in Figures S10, so that the one in which Markovian behavior is exhibited can be identified and chosen for further analysis.

3. Transition path theory analysis. In addition to the thermodynamics and kinetics information it contains, the Markovian TPM also contains mechanistic information for a dynamic system. An established means of revealing such mechanistic information inherent in the TPM is the Transition Path Theory (TPT) analysis that identifies the most probable flux pathways of the system (80). TPT provides such pathways by constructing a flux matrix from the Markovian TPM. This matrix conversion has been documented in detail $(80,81)$ and its implementation is discussed in our previous publication (30). Although directly applicable to MSM in the microstate space (on the order of hundreds to thousands of states), TPT analysis is usually done on a macrostate MSM (on the order of tens of states) for a better visualization of flux pathways. Here we transitioned from the microstate-MSM to macrostate-MSM by using the Robust Perron Cluster Analysis $\left(\mathrm{PCCA}^{+}\right)$algorithm (82) that lumps microstates into macrostates using the sign structure of the MSM eigenvectors (this assumes that microstates with the same signs, positive or negative, in the MSM eigenvectors, will have similar kinetics (83)). Using the $\mathrm{PCCA}^{+}$algorithm we obtained 15 macrostates and by applying the TPT analysis to these macrostates we obtained the most probable flux pathways for the system.

List of abbreviations: SLC6: solute carrier 6, NSS: neurotransmitter:sodium symporter, DAT: dopamine transporter, hDAT: human dopamine transporter, SERT: serotonin transporter, TM: transmembrane, MSM: Markov State Model, tICA: time-structure based independent component analysis, TPM: transition probability matrix, TPT: transition path theory 


\section{Declarations}

Competing interests: The authors declare that they have no competing interests.

Funding: The work was supported by NIH Grants P01 DA012408, R01 DA041510 and in part U54 GM087519.

Authors' contributions: All authors contributed to conceiving the project and experimental design, A.M.R. did the analysis and carried out the MSM construction, G.K. carried out the MD simulations, all authors participated in the interpretation of results and in writing the manuscript.

Acknowledgments: The following computational resources are gratefully acknowledged: resources of the Oak Ridge Leadership Computing Facility (ALCC allocation BIP109) at the Oak Ridge National Laboratory, which is supported by the Office of Science of the U.S. Department of Energy under Contract No. DE-AC05-00OR22725; an allocation at the National Energy Research Scientific Computing Center (NERSC, repository m1710) supported by the Office of Science of the U.S. Department of Energy under Contract No. DE-AC02- 05CH11231; and the computational resources of the David A. Cofrin Center for Biomedical Information in the HRH Prince Alwaleed Bin Talal Bin Abdulaziz Alsaud Institute for Computational Biomedicine at Weill Cornell Medical College.

\section{References}

1. Broer, S., and Gether, U. (2012) The solute carrier 6 family of transporters. $B r J$ Pharmacol 167, 256-278

2. Sulzer, D., Sonders, M. S., Poulsen, N. W., and Galli, A. (2005) Mechanisms of neurotransmitter release by amphetamines: a review. Prog Neurobiol 75, 406-433

3. Ng, J., Papandreou, A., Heales, S. J., and Kurian, M. A. (2015) Monoamine neurotransmitter disorders--clinical advances and future perspectives. Nat Rev Neurol 11, 567-584

4. Vaughan, R. A., and Foster, J. D. (2013) Mechanisms of dopamine transporter regulation in normal and disease states. Trends Pharmacol Sci 34, 489-496

5. Ritz, M. C., Lamb, R., and Kuhar, M. (1987) Cocaine receptors on dopamine transporters are related to self-administration of cocaine. Science 237, 1219-1223

6. Sulzer, D. (2011) How addictive drugs disrupt presynaptic dopamine neurotransmission. Neuron 69, 628-649

7. Shekar, A., Aguilar, J. I., Galli, G., Cozzi, N. V., Brandt, S. D., Ruoho, A. E., Baumann, M. H., Matthies, H. J., and Galli, A. (2017) Atypical dopamine efflux caused by 3, 4methylenedioxypyrovalerone (MDPV) via the human dopamine transporter. Journal of chemical neuroanatomy 83, 69-74

8. Bowton, E., Saunders, C., Erreger, K., Sakrikar, D., Matthies, H. J., Sen, N., Jessen, T., Colbran, R. J., Caron, M. G., and Javitch, J. A. (2010) Dysregulation of dopamine transporters via dopamine D2 autoreceptors triggers anomalous dopamine efflux 
associated with attention-deficit hyperactivity disorder. Journal of Neuroscience 30, 6048-6057

9. Bowton, E., Saunders, C., Reddy, I. A., Campbell, N. G., Hamilton, P. J., Henry, L. K., Coon, H., Sakrikar, D., Veenstra-VanderWeele, J. M., Blakely, R. D., Sutcliffe, J., Matthies, H. J., Erreger, K., and Galli, A. (2014) SLC6A3 coding variant Ala559Val found in two autism probands alters dopamine transporter function and trafficking. Transl Psychiatry 4, e464

10. Hamilton, P. J., Campbell, N. G., Sharma, S., Erreger, K., Herborg Hansen, F., Saunders, C., Belovich, A. N., Sahai, M. A., Cook, E. H., Gether, U., McHaourab, H. S., Matthies, H. J., Sutcliffe, J. S., and Galli, A. (2013) De novo mutation in the dopamine transporter gene associates dopamine dysfunction with autism spectrum disorder. Mol Psychiatry 18, $1315-1323$

11. Hansen, F. H., Skjorringe, T., Yasmeen, S., Arends, N. V., Sahai, M. A., Erreger, K., Andreassen, T. F., Holy, M., Hamilton, P. J., Neergheen, V., Karlsborg, M., Newman, A. H., Pope, S., Heales, S. J., Friberg, L., Law, I., Pinborg, L. H., Sitte, H. H., Loland, C., Shi, L., Weinstein, H., Galli, A., Hjermind, L. E., Moller, L. B., and Gether, U. (2014) Missense dopamine transporter mutations associate with adult parkinsonism and ADHD. J Clin Invest 124, 3107-3120

12. Mazei-Robison, M. S., Bowton, E., Holy, M., Schmudermaier, M., Freissmuth, M., Sitte, H. H., Galli, A., and Blakely, R. D. (2008) Anomalous dopamine release associated with a human dopamine transporter coding variant. Journal of Neuroscience 28, 7040-7046

13. Mergy, M. A., Gowrishankar, R., Gresch, P. J., Gantz, S. C., Williams, J., Davis, G. L., Wheeler, C. A., Stanwood, G. D., Hahn, M. K., and Blakely, R. D. (2014) The rare DAT coding variant Val559 perturbs DA neuron function, changes behavior, and alters in vivo responses to psychostimulants. Proceedings of the National Academy of Sciences 111, E4779-E4788

14. Ng, J., Zhen, J., Meyer, E., Erreger, K., Li, Y., Kakar, N., Ahmad, J., Thiele, H., Kubisch, C., and Rider, N. L. (2014) Dopamine transporter deficiency syndrome: phenotypic spectrum from infancy to adulthood. Brain 137, 1107-1119

15. Sakrikar, D., Mazei-Robison, M. S., Mergy, M. A., Richtand, N. W., Han, Q., Hamilton, P. J., Bowton, E., Galli, A., Veenstra-Vanderweele, J., Gill, M., and Blakely, R. D. (2012) Attention deficit/hyperactivity disorder-derived coding variation in the dopamine transporter disrupts microdomain targeting and trafficking regulation. J Neurosci 32, 5385-5397

16. Yamashita, A., Singh, S. K., Kawate, T., Jin, Y., and Gouaux, E. (2005) Crystal structure of a bacterial homologue of $\mathrm{Na}+/ \mathrm{Cl}$--dependent neurotransmitter transporters. Nature 437, 215-223

17. Penmatsa, A., Wang, K. H., and Gouaux, E. (2013) X-ray structure of dopamine transporter elucidates antidepressant mechanism. Nature 503, 85-90

18. Malinauskaite, L., Quick, M., Reinhard, L., Lyons, J. A., Yano, H., Javitch, J. A., and Nissen, P. (2014) A mechanism for intracellular release of $\mathrm{Na}+$ by neurotransmitter/sodium symporters. Nat Struct Mol Biol 21, 1006-1012

19. Kantcheva, A. K., Quick, M., Shi, L., Winther, A.-M. L., Stolzenberg, S., Weinstein, H., Javitch, J. A., and Nissen, P. (2013) Chloride binding site of neurotransmitter sodium symporters. Proceedings of the National Academy of Sciences 110, 8489-8494

20. Khelashvili, G., Doktorova, M., Sahai, M. A., Johner, N., Shi, L., and Weinstein, H. (2015) Computational modeling of the N-terminus of the human dopamine transporter and its interaction with PIP2-containing membranes. Proteins: Structure, Function, and Bioinformatics 83, 952-969 
bioRxiv preprint doi: https://doi.org/10.1101/204164; this version posted January 30, 2018. The copyright holder for this preprint (which was not certified by peer review) is the author/funder, who has granted bioRxiv a license to display the preprint in perpetuity. It is made available under aCC-BY-NC-ND 4.0 International license.

21. Fenollar-Ferrer, C., Stockner, T., Schwarz, T. C., Pal, A., Gotovina, J., Hofmaier, T., Jayaraman, K., Adhikary, S., Kudlacek, O., and Mehdipour, A. R. (2014) Structure and regulatory interactions of the cytoplasmic terminal domains of serotonin transporter. Biochemistry 53, 5444-5460

22. Khoshbouei, H., Sen, N., Guptaroy, B., Johnson, L., Lund, D., Gnegy, M. E., Galli, A., and Javitch, J. A. (2004) N-terminal phosphorylation of the dopamine transporter is required for amphetamine-induced efflux. PLoS Biol 2, E78

23. Moritz, A. E., Rastedt, D. E., Stanislowski, D. J., Shetty, M., Smith, M. A., Vaughan, R. A., and Foster, J. D. (2015) Reciprocal Phosphorylation and Palmitoylation Control Dopamine Transporter Kinetics. J Biol Chem 290, 29095-29105

24. Binda, F., Dipace, C., Bowton, E., Robertson, S. D., Lute, B. J., Fog, J. U., Zhang, M., Sen, N., Colbran, R. J., and Gnegy, M. E. (2008) Syntaxin 1A interaction with the dopamine transporter promotes amphetamine-induced dopamine efflux. Molecular pharmacology 74, 1101-1108

25. Fog, J. U., Khoshbouei, H., Holy, M., Owens, W. A., Vaegter, C. B., Sen, N., Nikandrova, Y., Bowton, E., McMahon, D. G., and Colbran, R. J. (2006) Calmodulin kinase II interacts with the dopamine transporter $\mathrm{C}$ terminus to regulate amphetamineinduced reverse transport. Neuron 51, 417-429

26. Khelashvili, G., Stanley, N., Sahai, M. A., Medina, J., LeVine, M. V., Shi, L., De Fabritiis, G., and Weinstein, H. (2015) Spontaneous inward opening of the dopamine transporter is triggered by PIP2-regulated dynamics of the N-terminus. ACS Chem Neurosci 6, 1825-1837

27. Cheng, M. H., and Bahar, I. (2015) Molecular mechanism of dopamine transport by human dopamine transporter. Structure 23, 2171-2181

28. Shi, L., Quick, M., Zhao, Y., Weinstein, H., and Javitch, J. A. (2008) The mechanism of a neurotransmitter:sodium symporter--inward release of $\mathrm{Na}+$ and substrate is triggered by substrate in a second binding site. Mol Cell 30, 667-677

29. Tavoulari, S., Margheritis, E., Nagarajan, A., DeWitt, D. C., Zhang, Y.-W., Rosado, E., Ravera, S., Rhoades, E., Forrest, L. R., and Rudnick, G. (2016) Two Na+ sites control conformational change in a neurotransmitter transporter homolog. Journal of Biological Chemistry 291, 1456-1471

30. Razavi, A. M., Khelashvili, G., and Weinstein, H. (2017) A Markov state-based quantitative kinetic model of sodium release from the dopamine transporter. Scientific reports 7,40076

31. Cartier, E., Hamilton, P., Belovich, A. N., Shekar, A., Campbell, N. G., Saunders, C., Andreassen, T. F., Gether, U., Veenstra-Vanderweele, J., Sutcliffe, J. S., Ulery-Reynolds, P. G., Erreger, K., Matthies, H. J., and Galli, A. (2015) Rare Autism-Associated Variants Implicate Syntaxin 1 (STX1 R26Q) Phosphorylation and the Dopamine Transporter (hDAT R51W) in Dopamine Neurotransmission and Behaviors. EBioMedicine 2, 135 146

32. Hamilton, P. J., Belovich, A. N., Khelashvili, G., Saunders, C., Erreger, K., Javitch, J. A., Sitte, H. H., Weinstein, H., Matthies, H. J., and Galli, A. (2014) PIP2 regulates psychostimulant behaviors through its interaction with a membrane protein. Nat Chem Biol 10, 582-589

33. McGibbon, R. T., Beauchamp, K. A., Harrigan, M. P., Klein, C., Swails, J. M., Hernández, C. X., Schwantes, C. R., Wang, L.-P., Lane, T. J., and Pande, V. S. (2015) MDTraj: A modern open library for the analysis of molecular dynamics trajectories. Biophysical journal 109, 1528-1532 
bioRxiv preprint doi: https://doi.org/101101/204164; this version posted January 30, 2018. The copyright holder for this preprint (which was not certified by peer review) is the author/funder, who has granted bioRxiv a license to display the preprint in perpetuity. It is made available under

34. Kern, C., Erdem, F. A., El-Kasaby, A., Sandtner, W., Freissmuth, M., and Sucic, S. (2017) The N Terminus Specifies the Switch between Transport Modes of the Human Serotonin Transporter. Journal of Biological Chemistry 292, 3603-3613

35. LeVine, M. V., Cuendet, M. A., Khelashvili, G., and Weinstein, H. (2016) Allosteric mechanisms of molecular machines at the membrane: transport by sodium-coupled symporters. Chemical reviews 116, 6552-6587

36. LeVine, M. V., Cuendet, M. A., Razavi, A. M., Khelashvili, G., and Weinstein, H. (2018) Thermodynamic Coupling Function Analysis of Allosteric Mechanisms in the Human Dopamine Transporter. Biophysical Journal https://doi.org/10.1016/j.bpj.2017.10.030

37. Anderluh, A., Hofmaier, T., Klotzsch, E., Kudlacek, O., Stockner, T., Sitte, H. H., and Schütz, G. J. (2017) Direct PIP2 binding mediates stable oligomer formation of the serotonin transporter. Nature communications 8, 14089

38. Penmatsa, A., and Gouaux, E. (2013) How LeuT shapes our understanding of the mechanisms of sodium-coupled neurotransmitter transporters. J Physiol 592, 863-869

39. Gether, U., Andersen, P. H., Larsson, O. M., and Schousboe, A. (2006) Neurotransmitter transporters: molecular function of important drug targets. Trends Pharmacol Sci 27, 375-383

40. Beuming, T., Shi, L., Javitch, J. A., and Weinstein, H. (2006) A comprehensive structurebased alignment of prokaryotic and eukaryotic neurotransmitter/Na+ symporters (NSS) aids in the use of the LeuT structure to probe NSS structure and function. Molecular pharmacology 70, 1630-1642

41. Li, J., Wen, P.-C., Moradi, M., and Tajkhorshid, E. (2015) Computational characterization of structural dynamics underlying function in active membrane transporters. Current opinion in structural biology 31, 96-105

42. Buchmayer, F., Schicker, K., Steinkellner, T., Geier, P., Stübiger, G., Hamilton, P. J., Jurik, A., Stockner, T., Yang, J.-W., and Montgomery, T. (2013) Amphetamine actions at the serotonin transporter rely on the availability of phosphatidylinositol-4, 5bisphosphate. Proceedings of the National Academy of Sciences 110, 11642-11647

43. Sweeney, C. G., Tremblay, B. P., Stockner, T., Sitte, H. H., and Melikian, H. E. (2017) Dopamine Transporter Amino and Carboxyl Termini Synergistically Contribute to Substrate and Inhibitor Affinities. Journal of Biological Chemistry 292, 1302-1309

44. Moritz, A. E., Foster, J. D., Gorentla, B. K., Mazei-Robison, M. S., Yang, J.-W., Sitte, H. H., Blakely, R. D., and Vaughan, R. A. (2013) Phosphorylation of dopamine transporter serine 7 modulates cocaine analog binding. Journal of Biological Chemistry 288, 20-32

45. Foster, J. D., Yang, J.-W., Moritz, A. E., ChallaSivaKanaka, S., Smith, M. A., Holy, M., Wilebski, K., Sitte, H. H., and Vaughan, R. A. (2012) Dopamine transporter phosphorylation site threonine 53 regulates substrate reuptake and amphetaminestimulated efflux. Journal of Biological Chemistry 287, 29702-29712

46. Cremona, M. L., Matthies, H. J., Pau, K., Bowton, E., Speed, N., Lute, B. J., Anderson, M., Sen, N., Robertson, S. D., and Vaughan, R. A. (2011) Flotillin-1 is essential for PKCtriggered endocytosis and membrane microdomain localization of DAT. Nature neuroscience 14, 469-477

47. Sucic, S., Dallinger, S., Zdrazil, B., Weissensteiner, R., Jørgensen, T. N., Holy, M., Kudlacek, O., Seidel, S., Cha, J. H., and Gether, U. (2010) The N terminus of monoamine transporters is a lever required for the action of amphetamines. Journal of Biological Chemistry 285, 10924-10938

48. Li, J., Shaikh, S. A., Enkavi, G., Wen, P.-C., Huang, Z., and Tajkhorshid, E. (2013) Transient formation of water-conducting states in membrane transporters. Proceedings of the National Academy of Sciences 110, 7696-7701 

aCC-BY-NC-ND 4.0 International license.

49. Shaikh, S. A., and Tajkhorshid, E. (2010) Modeling and dynamics of the inward-facing state of a $\mathrm{Na}+/ \mathrm{Cl}-$ dependent neurotransmitter transporter homologue. PLoS computational biology 6, e1000905

50. Zomot, E., Gur, M., and Bahar, I. (2015) Microseconds simulations reveal a new sodiumbinding site and the mechanism of sodium-coupled substrate uptake by LeuT. Journal of Biological Chemistry 290, 544-555

51. Cheng, M. H., and Bahar, I. (2014) Complete mapping of substrate translocation highlights the role of LeuT N-terminal segment in regulating transport cycle. PLoS computational biology 10, e1003879

52. Khelashvili, G., and Weinstein, H. (2015) Functional mechanisms of neurotransmitter transporters regulated by lipid-protein interactions of their terminal loops. Biochimica et Biophysica Acta (BBA)-Biomembranes 1848, 1765-1774

53. Foster, J. D., and Vaughan, R. A. (2016) Phosphorylation mechanisms in dopamine transporter regulation. Journal of chemical neuroanatomy 83, 10-18

54. Rastedt, D., Foster, J., and Vaughan, R. (2015) Dopamine transporter expression and transport capacity is regulated by palmitoylation. The FASEB Journal 29, 768.764

55. Humphrey, W., Dalke, A., and Schulten, K. (1996) VMD: visual molecular dynamics. Journal of molecular graphics 14, 33-38

56. Webb, B., and Sali, A. (2014) Protein structure modeling with MODELLER. Protein Structure Prediction, 1-15

57. Phillips, J. C., Braun, R., Wang, W., Gumbart, J., Tajkhorshid, E., Villa, E., Chipot, C., Skeel, R. D., Kale, L., and Schulten, K. (2005) Scalable molecular dynamics with NAMD. Journal of computational chemistry 26, 1781-1802

58. Harvey, M. J., Giupponi, G., and Fabritiis, G. D. (2009) ACEMD: accelerating biomolecular dynamics in the microsecond time scale. Journal of chemical theory and computation 5, 1632-1639

59. Dainese, E., De Fabritiis, G., Sabatucci, A., Oddi, S., Angelucci, C. B., Di Pancrazio, C., Giorgino, T., Stanley, N., Del Carlo, M., and Cravatt, B. F. (2014) Membrane lipids are key modulators of the endocannabinoid-hydrolase FAAH. Biochemical Journal 457, 463472

60. Piana, S., Lindorff-Larsen, K., Dirks, R. M., Salmon, J. K., Dror, R. O., and Shaw, D. E. (2012) Evaluating the effects of cutoffs and treatment of long-range electrostatics in protein folding simulations. PLoS One 7, e39918

61. Kapoor, A., Martinez-Rosell, G., Provasi, D., Fabritiis, G., and Filizola, M. (2017) Dynamic and Kinetic Elements of $\mu$-Opioid Receptor Functional Selectivity. Scientific Reports 7, 11255

62. Plattner, N., Doerr, S., De Fabritiis, G., and Noé, F. (2017) Complete protein-protein association kinetics in atomic detail revealed by molecular dynamics simulations and Markov modelling. Nature Chemistry

63. Morra, G., Razavi. A. M., Pandey, K., Weinstein, H., Menon, A. K., and Khelashvili, G. (2017) Mechanisms of lipid scrambling by the G protein-coupled receptor opsin.

Structure in press

64. Guixà-González, R., Albasanz, J. L., Rodriguez-Espigares, I., Pastor, M., Sanz, F., MartíSolano, M., Manna, M., Martinez-Seara, H., Hildebrand, P. W., and Martín, M. (2017) Membrane cholesterol access into a G-protein-coupled receptor. Nature Communications 8,14505

65. Chodera, J. D., Swope, W. C., Pitera, J. W., and Dill, K. A. (2006) Long-Time Protein Folding Dynamics from Short-Time Molecular Dynamics Simulations. Multiscale Model. Simul. 5, 1214-1226 
bioRxiv preprint doi: https://doi.org/10.1101/204164; this version posted January 30, 2018. The copyright holder for this preprint (which was not certified by peer review) is the author/funder, who has granted bioRxiv a license to display the preprint in perpetuity. It is made available under aCC-BY-NC-ND 4.0 International license.

66. Prinz, J.-H., Wu, H., Sarich, M., Keller, B., Senne, M., Held, M., Chodera, J. D., Schütte, C., and Noé, F. (2011) Markov models of molecular kinetics: Generation and validation. The Journal of chemical physics 134, 174105

67. Pande, V. S., Beauchamp, K., and Bowman, G. R. (2010) Everything you wanted to know about Markov State Models but were afraid to ask. Methods 52, 99-105

68. Voelz, V. A., Bowman, G. R., Beauchamp, K., and Pande, V. S. (2010) Molecular simulation of ab initio protein folding for a millisecond folder NTL9 (1-39). Journal of the American Chemical Society 132, 1526-1528

69. Beauchamp, K. A., McGibbon, R., Lin, Y. S., and Pande, V. S. (2012) Simple few-state models reveal hidden complexity in protein folding. Proc Natl Acad Sci U S A 109, 17807-17813

70. Lapidus, L. J., Acharya, S., Schwantes, C. R., Wu, L., Shukla, D., King, M., DeCamp, S. J., and Pande, V. S. (2014) Complex pathways in folding of protein G explored by simulation and experiment. Biophysical journal 107, 947-955

71. Voelz, V. A., Jäger, M., Yao, S., Chen, Y., Zhu, L., Waldauer, S. A., Bowman, G. R., Friedrichs, M., Bakajin, O., and Lapidus, L. J. (2012) Slow unfolded-state structuring in Acyl-CoA binding protein folding revealed by simulation and experiment. Journal of the American Chemical Society 134, 12565-12577

72. Kohlhoff, K. J., Shukla, D., Lawrenz, M., Bowman, G. R., Konerding, D. E., Belov, D., Altman, R. B., and Pande, V. S. (2014) Cloud-based simulations on Google Exacycle reveal ligand modulation of GPCR activation pathways. Nat Chem 6, 15-21

73. Adelman, J. L., Ghezzi, C., Bisignano, P., Loo, D. D., Choe, S., Abramson, J., Rosenberg, J. M., Wright, E. M., and Grabe, M. (2016) Stochastic steps in secondary active sugar transport. Proceedings of the National Academy of Sciences 113, E3960E3966

74. Perez-Hernandez, G., Paul, F., Giorgino, T., De Fabritiis, G., and Noe, F. (2013) Identification of slow molecular order parameters for Markov model construction. $J$ Chem Phys 139, 015102

75. Schwantes, C. R., and Pande, V. S. (2013) Improvements in Markov State Model Construction Reveal Many Non-Native Interactions in the Folding of NTL9. J. Chem. Theory Comput. 9, 2000-2009

76. Oja, E., and Hyvarinen, A. (2000) Independent component analysis: algorithms and applications. Neural networks 13, 411-430

77. Naritomi, Y., and Fuchigami, S. (2011) Slow dynamics in protein fluctuations revealed by time-structure based independent component analysis: The case of domain motions. $J$. Chem. Phys. 134, 065101

78. Beauchamp, K. A., Bowman, G. R., Lane, T. J., Maibaum, L., Haque, I. S., and Pande, V. S. (2011) MSMBuilder2: Modeling Conformational Dynamics at the Picosecond to Millisecond Scale. J Chem Theory Comput 7, 3412-3419

79. Harrigan, M. P., Sultan, M. M., Hernández, C. X., Husic, B. E., Eastman, P., Schwantes, C. R., Beauchamp, K. A., McGibbon, R. T., and Pande, V. S. (2017) MSMBuilder: Statistical Models for Biomolecular Dynamics. Biophysical journal 112, 10-15

80. Berezhkovskii, A., Hummer, G., and Szabo, A. (2009) Reactive flux and folding pathways in network models of coarse-grained protein dynamics. J Chem Phys 130, 205102

81. Kube, S., and Weber, M. (2007) A coarse graining method for the identification of transition rates between molecular conformations. The Journal of chemical physics 126, 024103 
bioRxiv preprint doi: https://doi.org/10.1101/204164; this version posted January 30, 2018. The copyright holder for this preprint (which was not certified by peer review) is the author/funder, who has granted bioRxiv a license to display the preprint in perpetuity. It is made available under aCC-BY-NC-ND 4.0 International license.

82. Deuflhard, P., and Weber, M. (2005) Robust Perron cluster analysis in conformation dynamics. Linear algebra and its applications 398, 161-184

83. Chodera, J. D., and Noé, F. (2014) Markov state models of biomolecular conformational dynamics. Current Opinion in Structural Biology 25, 135-144 